\title{
Serum Reproductive hormone levels in male symptomatic HIV/AIDS patients on Antiretroviral therapy negative to Malaria parasite in Nnewi, Anambra State, Nigeria
}

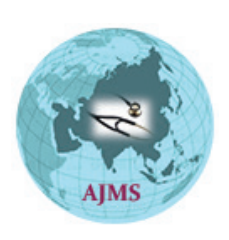

\author{
Priscilla Ifeoma Ezeugwunne ${ }^{1 *}$, Chukwuemeka Emmanuel Ogbodo ${ }^{2}$, \\ Adamma Rosemary Analike ${ }^{3}$, Nwando Chikaodili Obi-Ezeani ${ }^{4}$, Joy Ifeoma Onuora ${ }^{5}$, \\ Nwabunwanne Victor Oguaka ${ }^{6}$, Kalu Ubou Amah ${ }^{7}$, Chukwuemeka Michael Ugwur, \\ Chinedum Charles Onyenekwe ${ }^{9}$, Eberendu Joseph Ahaneku ${ }^{10}$
}

\begin{abstract}
${ }^{1,6}$ Lecturer, Department of Human Biochemistry, Faculty of Basic Medical Sciences, Nnamdi Azikiwe University, Nnewi, Nigeria, ${ }^{2,8}$ Senior Medical Laboratory Scientist, Department of Medical Laboratory Science, Faculty of Health Sciences, Nnamdi Azikiwe University, Nnewi, Nigeria, ${ }^{3,5}$ Chief Medical Laboratory Scientist, Department of Chemical Pathology, Faculty of Medicine, Nnamdi Azikiwe University, Nnewi, Nigeria, ${ }^{4}$ Senior Medical Laboratory Scientist, Department of Chemical Pathology, Chukwuemeka Odumegwu Ojukwu University, Awka, Nigeria, ${ }^{7}$ Senior lecturer, ${ }^{9,10}$ Professor, Department of Chemical Pathology, Faculty of Medicine, Nnamdi Azikiwe University, Nnewi, Nigeria
\end{abstract}

Background: AIDS is an endemic disease that causes death among young adults worldwide especially in Nigeria. Aims and Objectives: This study investigated the serum reproductive hormone levels in symptomatic HIV/AIDS male subjects on ART who are negative to malaria parasite in Nnewi, Anambra State, Nigeria. Materials and Methods: A total of 274 adult male participants aged between 18 and 60 years were randomly recruited, and grouped into: symptomatic HIV (stage 11) infected male participants on ART (A: $n=69$ ), Symptomatic HIV subjects not on ART (B: $n=69$ ), Asymptomatic HIV positive subjects (C: $n=68$ ) and HIV seronegative subjects ( $D: n=68$ ). Serum was used to assay for PSA, LH, FSH, Estrogen, Testosterone, Progesterone and Prolactin levels. Analysis of variance and student t-test were used for data analyses. Results: The serum levels of PSA, FSH, Estrogen, Testosterone, Progesterone and Prolactin were significantly different amongst the groups at $p<0.05$ respectively. There were significantly higher levels of PSA, Estrogen, Progesterone but lower levels of Testosterone and Prolactin in subjects on ART compared with control at $p<0.05$ respectively. There were significantly higher levels of PSA, FSH, Estrogen,Progesterone but lower levels of Testosterone in subjects not on ART compared with control at $p<0.05$ respectively. Conclusion: The reduction on serum levels of Testosterone and higher levels in FSH, PSA, Estrogen, and Progesterone may reveal presence of hypogonadism, primary testicular failure, prostate abnormalities such as cancer and hyperprogesteronaemia, in symptomatic HIV positives.

Key words: HIV; AIDS; Malaria negative; male subjects; reproductive hormones; ART DOI: 10.3126/ajms.v10i3.22505 E-ISSN: 2091-0576 P-ISSN: 2467-9100

\section{INTRODUCTION}

Acquired immunodeficiency syndrome (AIDS) is an endemic disease that causes death among young adults worldwide. ${ }^{1}$ AIDS is caused by two lenti-viruses, human immunodeficiency viruses (HIV) types 1 and $2,{ }^{2}$ with HIV type 1 strains classified into $\mathrm{M}, \mathrm{O}$ and $\mathrm{N}$ groups. $^{3}$
However, the majorities of HIV-1 viral strains are classified as group $\mathrm{M}$ which has various subtypes (A to $\mathrm{K})^{3}$ and are distributed worldwide; with subtype $\mathrm{C}$ infections endemic to sub-Saharan Africa, India and Brazil. HIV-1 primarily infects $\mathrm{CD} 4^{+} \mathrm{T}$ cells and macrophages. ${ }^{4} \mathrm{HIV}$ transmission occurs through exposure to contaminated body fluids, such as blood, ${ }^{5}$ or breast milk; ${ }^{6}$ with possible routes of 
transmission including blood transfusions, intravenous drug use, mother-child transmission and during sexual intercourse. ${ }^{5-8}$ Indeed, the United Nations has termed HIV and AIDS the greatest overwhelming public health problems that the world has ever encountered. ${ }^{9,10}$ In fact, Nigeria has the second largest HIV epidemic in the world. ${ }^{11}$ Although HIV prevalence among adults is much less $(2.9 \%)$ than other sub-Saharan African countries such as South Africa (18.9\%) and Zambia (12.4\%), the size of Nigeria's population means 3.6 million people were living with HIV in 2016. ${ }^{11}$ However, recently, the global health sector strategy on HIV/AIDS 2011-2015 $5^{12}$ has galvanized global and country action that has helped halt and reverse the AIDS epidemic. During this period, HIV treatment coverage was expanded rapidly with well over 17 million people living with HIV on antiretroviral therapy by the end of 2015; with new HIV infections and deaths declined. ${ }^{13}$ However, there is no need for complacency as more work is needed in order to bring to minimal the menace of the HIV/AIDS invasion on the human population.

Reproductive endocrinology encompasses the hormones of the hypothalamic-pituitary-gonadal axis and the adrenal glands. ${ }^{14}$ The endocrine reproductive system produces reproductive hormones such as FSH, LH, Testosterone, Estrogen, Progesterone, Prolactin and Cortisol into general circulation. ${ }^{15,16}$ These hormones are crucial for proper reproductive function. ${ }^{14}$ However, many alterations in endocrine functions have been reported in association with human immunodeficiency virus (HIV) infection and the acquired immunodeficiency syndrome (AIDS) in both early and late stages of HIV infection. ${ }^{17}$ These changes may be as a result of the systemic effects of HIV, opportunistic infections, infiltration by a neoplasm or as a complication of treatment. Hypogonadism has been reported to increase in HIV disease ${ }^{18}$, and gonadal dysfunctions are common among men as compared to women. ${ }^{19}$ Also, HIV infected person has been reported to have increased serum LH and FSH levels. ${ }^{20}$ Therefore, this study investigated the serum reproductive hormone levels in male symptomatic HIV/AIDS patients on antiretroviral therapy negative to malaria parasite in Nnewi, Anambra State, Nigeria.

\section{MATERIALS AND METHODS}

\section{Subjects}

This is a case controlled study designed to evaluate the serum hormonal levels in malaria uninfected symptomatic HIV (Stage II) male subjects on antiretroviral therapy in Nnewi, South Eastern Nigeria. A total of 274 adult male participants aged between 18 and $60(42 \pm 13)$ years were randomly recruited at the Voluntary Counseling and Testing (VCT) Centre in Nnamdi Azikiwe University Teaching
Hospital (NAUTH), Nnewi, Nigeria. Based on World Health Organisation (WHO) criteria for staging HIV, the participants were grouped as follows: symptomatic HIV (stage 11) infected male participants on ART $(\mathrm{n}=69)$. Lamivudine, $150 \mathrm{mg}$ twice daily, Stavudine, $40 \mathrm{mg}$ twice daily and Nevirapine, $200 \mathrm{mg}$ twice daily: this was administered to the symptomatic HIV stage 11 subjects on ART. Symptomatic HIV subjects not on ART (n= 69), Asymptomatic HIV positive subjects $(n=68)$ and HIV seronegative subjects $(n=68)$. The subjects were given informed consent, while the study design was approved by the ethical committee of Nnamdi Azikiwe University Teaching Hospital, Nnewi, Nigeria. $5 \mathrm{ml}$ of blood sample were collected from each of the participant in the groups. The participants were screened for HIV infection using Immunoassay and Immunochromatographic method. The serum was used for the estimation of PSA, FSH, LH, Testosterone, Estrogen, Progesterone, and Prolactin levels. The serum samples were stored at $-20^{\circ} \mathrm{C}$ until analyzed.

Antibodies to HIV-1 and HIV-2 in human plasma were determined using Abbott determine TM HIV -1 andHIV-2 kit, which is an in-vitro visually read immunoassay (Abbott Japan Co.Ltd.Tokyo, Japan) and HIV-1 and 2 STAT-PAK Assay kit, which is an Immunochromatographic test for the quantitative detection of antibodies to HIV-1 and HIV-2 in Human plasma (CHEMBIO Diagnostic system, Inc, New York, USA). Determination of PSA, LH, FSH, Testosterone, Estradiol, Progesterone and Prolactin were done using Enzyme Linked Immunosorbent assay (ELISA) kits (Randox Laboratories Limited, U.K) respectively.

\section{Statistical analysis}

The data obtained was statistically analyzed using Statistical Package for Social Sciences (SPSS) version 16.0. One of way analysis of variance (ANOVA) and students't-test were used to compare means. The results were expressed as mean $\pm S D$ and confidence limits was chosen at $95 \%$ ( $<<0.05)$. $\mathrm{P}<0.05$ was considered statistically significant while $\mathrm{P}>0.05$ was insignificant.

\section{RESULTS}

The result of analysis of variance showed that the mean serum levels of PSA, FSH, Estrogen, Testosterone, Progesterone and Prolactin were significantly different amongst the group $(\mathrm{F}=12.07,5.79,22.69,18.03,14.03$ AND 8.04) $(\mathrm{P}<0.05)$ respectively, whereas, $\mathrm{LH}$ did not differ significantly amongst the group $(\mathrm{F}=1.94 ; \mathrm{P}>0.05)$ (Table 1$)$.

The mean serum PSA ( $\mathrm{ng} / \mathrm{ml}$ ) level did not differ significantly in HIV seropositive participants on ART (7.414.24) compared with HIV seropositive participants 
not on ART (7.91 5 5.17) $(\mathrm{p}=0.93)$. Also the mean serum PSA level in HIV seropositive participants on ART did not differ significantly compared with Asymptomatic HIV positive subjects $(\mathrm{P}>0.05)$. However, the serum PSA value in HIV seropositive participants on ART was significantly lower than the value in control group $(\mathrm{p}=0.000)$.

The mean serum LH (miu/ml) and FSH levels was not significantly different in HIV seropositive participants on ART compared with HIV seropositive participants not on ART, Asymtomatic HIV positive subjects and control group ( $>0.05$ ) respectively.

There was no significant difference in the mean serum Estrogen ( $\mathrm{pg} / \mathrm{ml}$ ) levels in HIV seropositive participants on ART compared with HIV seropositives not on ART $(\mathrm{P}>0.05)$, but significant statistical increases in the mean serum levels of Estrogen in HIV seropositive participants on ART than in Asymptomatic HIV positives and control subjects $(\mathrm{p}<0.05)$ respectively.

The mean $( \pm \mathrm{SD})$ of serum Testosterone $(\mathrm{ng} / \mathrm{ml})$ levels in HIV seropositive participants on ART was significantly lower compared with the corresponding value in the control group (2.58 \pm 1.58 Vs $4.80 \pm 1.75 ; \mathrm{p}=0.00)$. However, no significant mean differences were observed between values in HIV seropositive participants on ART and not on ART $(\mathrm{P}>0.05)$.

The mean $( \pm \mathrm{SD})$ of serum progesterone $(\mathrm{ng} / \mathrm{ml})$ level did not differ significantly in HIV seropositive participants on ART compared with HIV seropositive participants not on ART and Asymptomatic HIV positives ( $\mathrm{P}>0.05)$, whereas the mean $( \pm S D)$ of serum progesterone level was significantly higher in HIV seropositive participants on ART than in control group $(2.42 \pm 1.73$ Vs $1.09 \pm 1.19$; $\mathrm{p}=0.00$ ).

The mean $( \pm \mathrm{SD})$ of serum Prolactin $(\mathrm{ng} / \mathrm{ml})$ levels in HIV seropositive participants on ART was significantly lower compared with the corresponding value in the HIV seropositive participants not on ART $(7.15 \pm 5.33$ Vs $10.33 \pm 3.90 ; \mathrm{p}=0.00)$, while the mean $( \pm \mathrm{SD})$ of serum Prolactin level in HIV seropositive participants on ART did not differ significantly than in Asymptomatic HIV positive subjects $(\mathrm{p}=0.20)$.

\section{DISCUSSION}

Human Immunodeficiency Virus (HIV) infection has been convincingly shown to increase opportunistic infection, risk of prostatitis, ${ }^{21}$ and several malignancies including testicular cancers, lymphomas, penile cancers ${ }^{22}$ and prostate cancers. ${ }^{23,24}$

The present study revealed a significantly elevated PSA levels in HIV/AIDS seropositive subjects on ART than in the HIV seronegative participants. Also, there was a significant difference in the mean value of PSA levels between the HIV/AIDS seropositive participants on ART compared with HIV/AIDS seropositive participants not on ART. Again, comparison of PSA level between HIV/AIDS seropositive subjects on ART and asymptomatic HIV positive participants revealed no significant statistical difference. These findings may suggest a link between

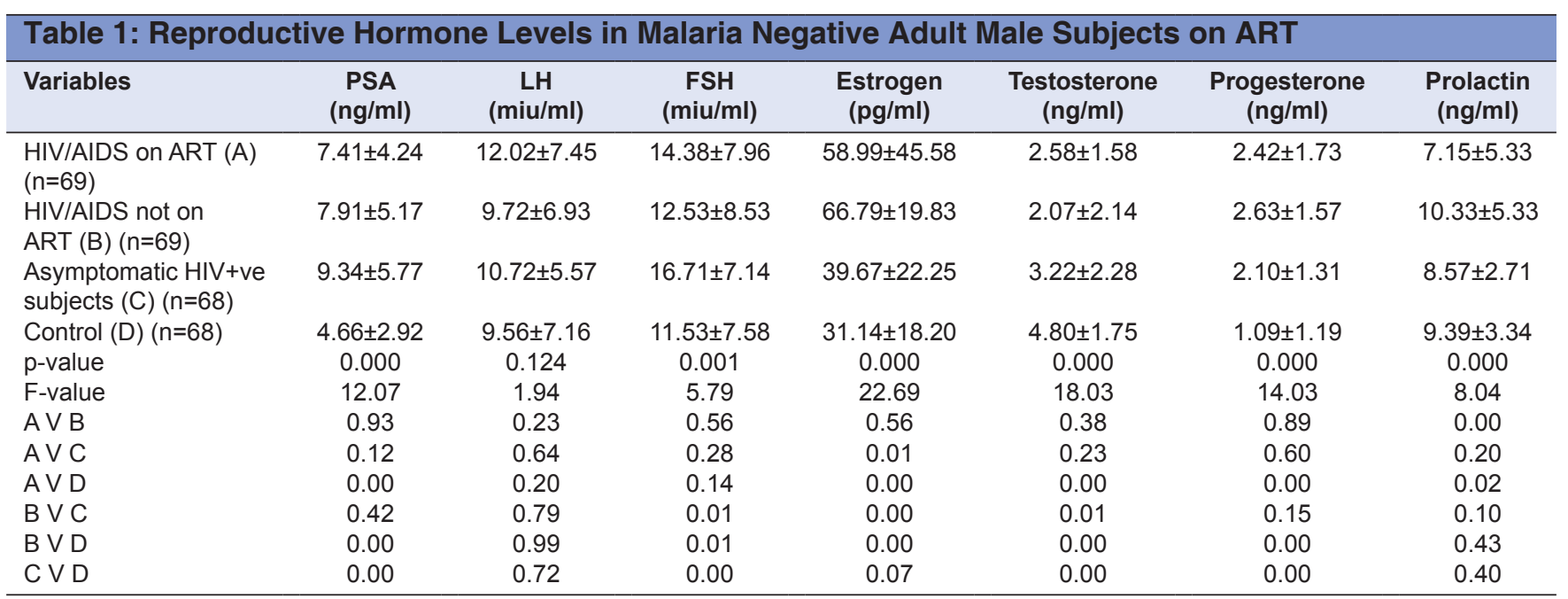

Fp=HIV on ART subjects, HIV not on ART subjects, Asymptomatic HIV subjects and HIV seronegative control group compared using ANOVA; A $\vee B=H I V$ on ART subjects compared with HIV not on ART subjects (using student's t-test);

A V C =HIV on ART subjects compared with Asymptomatic HIV subjects (using student's t-test);

$A \vee D=H I V$ on ART subjects compared with HIV seronegative control subjects (using student's t-test);

$B \vee C=H I V$ not on ART subjects compared with Asymptomatic HIV subjects (using student's t-test);

B V D=HIV not on ART subjects compared with HIV seronegative control subjects (using student's t-test);

$C V D=$ Asymptomatic HIV subjects compared with HIV seronegative control subjects (using student's t-test) 
HIV/AIDS and prostate cancer risk. However, the underlying mechanism behind this increase is not clear. This finding is in consonance with the report of Vianna et al. ${ }^{25}$ Several other authors have reported the occurrence of prostate carcinoma in HIV-positive men, ${ }^{26,27}$ although Julia et al. had earlier reported a lower incidence of prostate cancer among HIV-positive men than in HIV-Negative Men. ${ }^{28}$

In this study, the mean serum testosterone level was significantly decreased in the HIV/AIDS seropositive subjects on ART compared with the control $(2.42 \pm 1.73$ Vs $4.80 \pm 1.75 ; \mathrm{P}=0.000)$. This decrease may be indicative of hypogonadism among the studied population. This is in line with previous studies. ${ }^{29-32}$ Hypogonadism is a clinical condition characterized by low serum testosterone levels occurring in association with any of the signs and symptoms including sexual dysfunction, weight and muscle mass loss, fatique, depressed mood and anemia. . $^{33,34}$ This decrease may be as a result of the effect of HIV on the gonads, ${ }^{35}$ or due to cytokine effect; as HIV infection is known to upregulate tumour necrosis factor and interleukin- $1^{36}$, resulting in decreased testicular steroidogenesis.

However, both LH and FSH levels were raised, although not statistically significant in HIV/AIDS seropositive participants on ART than in the control subjects $(\mathrm{p}>0.05)$. This increase may be suggestive of subnormal or primary hypogonadism. This increase may be attributed to the severity of the infection. This finding is in agreement with other similar reports. ${ }^{37}$ Also, the mean FSH levels in the asymptomatic HIV positive subjects was significantly higher than in control group (16.71 \pm 7.14 Vs $11.53 \pm 7.58$; $\mathrm{p}=0.00$ ), whereas the mean serum LH level did not differ significantly $(p=0.99)$ between the asymptomatic HIV positive subjects and seronegative participants.

The present study showed a significant increase in the mean value of Estrogen concentration in HIV/AIDS seropositive participants on ART than in the control subjects. Also, this study revealed a significant decrease in the mean serum Estrogen levels in the asymptomatic HIV positive participants compared with the value obtained in the HIV/AIDS seropositive participants on ART $(p=0.01)$. This confirms the fact that the stimulatory effects of elevated serum LH and FSH concentrations on the testis increases conversion of testosterone to estradiol..$^{38}$ Estrogenic effect is a peripheral conversion of testosterone to Estrogen by Aromatase and Enolase. ${ }^{39}$ Also, the abnormal androgen metabolism which results in increased aromatization of testosterone to estradiol had earlier been reported in HIV positive men. ${ }^{40}$

Furthermore, there was a significant statistical increase in the mean serum progesterone concentrations in HIV / AIDS seropositive participants on ART than in the control subjects $(\mathrm{p}=0.00)$. This may be due to the stimulatory effect of HIV infection on the endocrine glands to release progesterone.

This study also observed that the serum prolactin level was significantly elevated in HIV/AIDS seropositive participants not on ART than in those on ART and control subjects respectively. This could be the resultant effect of the disease burden on the pituitary which causes an increase stimulation and secretion of prolactin into the circulation. The reduced prolactin level observed in participants on antiretroviral drugs may be due to the health recovery effect resulting from ART therapy.

\section{CONCLUSION}

This study revealed a stimulatory effect of HIV infection on the endocrine glands to release LH, FSH, Progesterone, Prolactin and Estrogen, with a concomitant inhibitory effect on the release of testosterone from the gonads.

\section{REFERENCES}

1. Amegor OF, Bigila DA, Oyesola OA, Oyesola TO and Buseni ST. Hematological changes in HIV patients placed on antiretroviral therapy in Markurdi, Benue State of Nigeria. Asian Journal of Epidemiology 2009; 2(4):97-103.

2. De Cock KM, Adjorlolo G, Ekpini E, Sibailly T, Kouadio J and Maran M. Epidemiology and transmission of HIV-2: Why there is no HIV-2 pandemic. Journal of American Medical Association 1993; 270:2083-2086.

3. Woodman Z and Williamson C. HIV molecular epidemiology: transmission and adaptation to human populations. Current Opinion in HIV AIDS 2009; 4:247-252.

4. Soni RS. Studies on the Cellular Factors and Hormones Controlling Hiv-1 Transmission in an Organ Culture Model [dissertation]. University of Pittsburgh., 2015.

5. Baggaley RBC, White R and Alary M. Risk of HIV-1 transmission for parenteral exposure and blood transfusion: a systematic review and meta-analysis. AIDS 2006; 20(6): 805-812.

6. Salazar-Gonzalez J, Salazar M, Learn G, Fouda G, Kang H, Mahlokozera T, et al. Origin and Evolution of HIV-1 in Breast Milk Determined by Single-Genome Amplification and Sequencing. Journal of Virology 2011; 85(6): 2751-2763.

7. Hariri $S$ and Me Kenna M. Epidemiology of Human immunodeficiency virus in the United States. Clinical Microbiology Review 2007; 20:474-488.

8. Dwyre D, Fernando L and Holland P. Hepatitis B, Hepatitis C and HIV Transfusion-Transmitted Infections in the $21^{\text {st }}$ Century. Vox Sang 2011; 100(1): 92-98.

9. United Nation Programme on HIVIAIDS/World Health Organization (UNAIDS/WHO) Press Release. HIV Infection Rates Decreasing in Several Countries but Globally Number of People Living with HIV Continue to Rise, 2005. Available at www.usaid.org/epi/2005/doc/docs/PR_EPIUpdateNov05en. pdf:1-3

10. Sule WF, Okonko IO, Yusuf OT, Donbraye E, Fadeyi A and Alli JA. HIV-1 and -2 Antibodies among Children in Anyigba, Kogi State, 
Nigeria. Asian Journal of Medical Sciences 2010; 2(4): 170-176.

11. NACA. National Strategic Framework on HIV andAIDS: 2017-2021, 2017. https://www.childrenandaids.org/sites/default/files/2017-11/ NATIONAL-HIV-AND-AIDS-STRATEGIC-FRAMEWORK.

12. The global health sector strategy on HIVIAIDS 2011-2015 is available at: http://apps.who.int/iris/ bitstream/10665/44606/1/9789241501651_eng.pdf.

13. World Health Organisation. Global Health Sector Strategy on HIV 2016-2021 towards Ending AIDS, 2016.

14. Carl AB, Edward RA and David EB. Reproductive disorders: In Tietz Fundamentals of Clinical Chemistry, Saunder Elsevier, 2008, Pp. 780.

15. Gluckman PD and Hanson MA. Evolution, development and timing of puberty. Trends in endocrinology and Metabolism 2006;17(1): 7-12.

16. Mancini T. Hyperprolactinemia and prolactinomas. Endocrinology and Metabolism Clinics of North America 2008; 37:67.

17. Grinspoon SK, Melmed S, Polonsky KS, Larsen PR, Kronenberg HM. Endocrinology of HIV and AIDS: In William textbook of Endocrinology. 12 ${ }^{\text {th }}$ ed. Philadelphia: Saunders Elsevier; 2011, Pp. 1675-1696.

18. Wagner G, Rabkin JG and Rabkin R. Illness stage, concurrent medications, and other correlates of low testosterone in men with HIV illness. Journal of Acquired Immune Deficiency Syndrome and Human Retrovirology 1995; 8:204-207.

19. Eleftharios I and Koutkia P. Diagnosis and Treatment of Androgen Deficiency in Human Immunodeficiency Virus-Infected men and women. Clinical Infectious Diseases 2001; 33: 857-864.

20. Burgoyne RW and Tan DH. Prolongation and quality of life for HIV-infected adults treated with high active antiretroviral therapy (HAART): a balancing act. Journal of Antimicrobial Chemotherapy 2008; 61(3): 469-473.

21. Leport C, Rousseau F, Perronne C, Salmon D, Joerg A and Vilde JL. Bacterial prostatitis in patients infected with the human immunodeficiency virus. Journal of Urology 1989; 141: 334-336.

22. Biggar RJ, Kirby KA, Atkinson J, McNeel TS and Engels E. Cancer risk in elderly persons withHIVIAIDS. Journal of Acquired Immune Deficiency Syndrome 2004; 36:861-868.

23. Pantanowitz L, Schlecht HP and Dezube BJ. The growing problem of non-AIDSdefining malignancies in HIV. Current Opinion in Oncology 2006; 18: 469-478.

24. Walters Z, Shamash J and Powles T. Prostate cancer in HIVpositive individuals: what we know and what we don't. Journal of HIV Therapy 2007; 12: 66-67.

25. Vianna LE, Lo Y and Klein RS. Serum prostate-specific antigen levelsinoldermen with oratriskofHIVinfection. HIVMedicine2006; 7: 471-476.

26. Schwartz JD and Prince D. Prostate cancer in HIV infection. AIDS 1996; 10: 797-798.

27. Furco A, Bani-Sadr F, Guymar S and Molina JM. Metastatic cancer of the prostate in a young 40 year-old HIV infected male patient. Presse Medicale 2003; 32: 930-931.

28. Julia LM, Chun RC, Wendy AL, Lanfang $X$, Daniel BK, Michael $\mathrm{AH}$, et al. Prostate Cancer Incidence and ProstateSpecific AntigenTesting among HIV-Positive and HIV-Negative Men. Journal of Acquired Immune Deficiency Syndrome 2014; 66:495-502.

29. Raffi F, Brisseau JM, Planchon B, Remi J.P, Barrier JH and Grolleau JY. Endocrine function in HIV-infected patients: a prospective study. AIDS 1991; 5: 729-733.

30. Dejucq $\mathrm{N}$ and Jegou $\mathrm{B}$. Viruses in the mammalian male genital tract and their effects on the reproductive system. Microbiology and Molecular Biology Reviews 2001; 65: 208-231.

31. Ezeugwunne IP, Onyenekwe CC, Ahaneku JE, Ifeanyichukwu M, Meludu SC, Onwurah OW, et al. Serum hormonal levels in HIVI AIDS infected male subjects on antiretroviraltherapy (ART) in Nnewi, Nigeria. International Journal of Biology and Chemical Science 2012; 6(4): 1409-1418.

32. Gomes AR, Souteiro P, Silva CG, Sousa-Pinto B, Almeida F, Sarmento A, et al. Prevalence of testosterone deficiency in HIV-infected men under antiretroviral therapy. BMC Infectious Diseases 2016; 16:628.

33. Bhasin S, Cunningham GR, Hayes FJ, Matsumoto AM, Snyder PJ and Swerdloff R.S. Testosterone therapy in adult men with androgen deficiency syndromes: an endocrine society clinical practice guideline. Journal of Clinical Endocrinology and Metabolism 2006; 91: 1995-2010.

34. Rhoden EL and Morgentaler A. Risks of testosteronereplacement therapy and recommendations for monitoring. New England Journal of Medicine 2004; 350: 482-492.

35. Roof R and Hall E. Gender differences inacute CNS trauma and stroke: neuroprotective effects of estrogen and progesterone. Journal of Neurotrauma 2000; 17(5):367-388.

36. Cotter AG and Powderly WG. Endocrine complications of human immunodeficiency virus infection: Hypogonadism, bone disease and tenofovir-related toxicity. Best Practical Research in Clinical Endocrinology and Metabolism 2011; 25:501-515.

37. Meena LP, Rai M, Singh SK, Chakravarty J, Singh A, Goel R, et al. Endocrine changes in male HIV patients. Journal of Association of Physicians of India 2011; 59:365-371.

38. Nicholas W, Miles L and lain S. Hypogonadism in the HIV-Infected Man. Current Treatment Options in Infectious Diseases 2017; 9:104-116.

39. Meinhardt $U$ and Mullis $P$. The essentialrole of the aromatase/ p450arom. Seminars in Reproductive Medicine 2002; 20(3): 277-284.

40. Richardson D, Goldmeier D, Frize G, Lamba H, De Souza Cand Kocsis A. Letrozole versus testosterone. A single-center pilot study of HIV-infected men who have sex with men on highly active anti-retroviral therapy (HAART) with hypoactive sexual desire disorder and raised estradiol levels. Journal of Sexual Medicine 2007; 4:502-508. 
Authors Contribution:

IPE, CCO, JEA- Concept and design of the study, manuscript preparation, statistically analyzed and interpreted, critical revision of the manuscript;

RAA, ECO - Concept and design of the study, critical revision of manuscript and review of the study; CNO, IJO- reviewed the literature, helped in preparing first draft of manuscript, collected data; VNO, UKA, MCU-collected data, statistically analyzed and interpreted, helped in preparing first draft of manuscript.

Work attributed to:

Department of Human Biochemistry, Department of Medical Laboratory Science; Department of Chemical Pathology Nnamdi Azikiwe University, Nnewi, Nigeria Department of Chemical Pathology, Chukwuemeka Odumegwu Ojukwu University, Awka, Nigeria

\section{Orcid ID:}

Dr. I.P. Ezeugwunne - id https://orcid.org/0000-0002-3775-6966

Mr. E.C. Ogbodo - https://orcid.org/0000-0002-2560-2995

Mrs. R.A. Analike - https://orcid.org/0000-0001-7970-9909

Mrs. C.N. Obi Ezeani - https://orcid.org/0000-0002-9722-5470

Mrs. I.J. Onuora - https://orcid.org/0000-0003-1828-0410

Dr. V.N. Oguaka - https://orcid.org/0000-0001-5561-3208

Dr. U.K. Amah - https://orcid.org/0000-0003-0843-5415

Mr. M.C. Ugwu - https://orcid.org/0000-0001-6605-4608

Prof. C.C. Onyenekwe - https://orcid.org/0000-0002-7011-4797

Prof. J.E. Ahaneku -(D) https://orcid.org/0000-0002-1652-2513

Source of Support: Nil, Conflict of Interest: None declared. 